\title{
O USO DO DESIGN DE PRODUTOS COMO UMA FORMA EMPREENDEDORA DE ENSINO-APRENDIZAGEM: UMA PRÁTICA POSSÍVEL?
}

\author{
Matheus Silva Castro ${ }^{1}$ \\ Matheus Felipe Silva ${ }^{2}$
}

\begin{abstract}
Resumo: $\mathrm{Na}$ tentativa de superar modelos educacionais excludentes e com processos de ensinoaprendizagem centralizados no professor, o início do século XXI viu surgir a pedagogia empreendedora, que visa a formação do aluno preocupado com a sociedade e a comunidade na qual está inserido. Como forma de despertar as habilidades empreendedoras dos alunos, principalmente os do ensino médio, o ensino do design de produtos pode levar os discentes à reflexão sobre o meio em que vivem, para que realizem mapeamento de problemas e busquem de soluções inovadoras. O objetivo dessa pesquisa foi apresentar alguns métodos de design de produtos e como eles podem ser adotados para o desenvolvimento do ensino-aprendizagem empreendedor. Para isso, o presente artigo parte de uma pesquisa exploratória de base documental e bibliográfica, construída a partir da interrelação entre a educação empreendedora, partindo do design de produtos, e suas possibilidades para o ensino médio no sentido do desenvolvimento de habilidades e competências dos/nos estudantes. Para tal apresentamos a Base Nacional Comum Curricular (BNCC) para o ensino médio na área de Ciências Humanas e Sociais Aplicadas e os Eixos Cognitivos Comuns das Matrizes de Referência vigentes para o Exame Nacional do Ensino Médio (ENEM). Em seguida, apresentamos três métodos de design de produtos: Processo de Desenvolvimento de Produtos, Gestâo Ágil de Projetos e Design Thinking. Por fim, relacionamos ferramentas do design de produtos e suas potencialidades no atendimento das habilidades e competências esperadas dos alunos do ensino médio.
\end{abstract}

Palavras-chave: design de produtos, empreendedorismo, pedagogia empreendedora.

1 Graduado em Engenharia de Produção pela Universidade de Franca UNIFRAN, Franca, São Paulo, Brasil. Mestrado interrompido em Engenharia de Produção pela Escola de Engenharia de São Carlos da Universidade de São Paulo USP, São Paulo, Brasil. E Especialista em Educação Empresarial pela Universidade Federal de São João del-Rei, Minas Gerais, Brasil. Atualmente é estudante de Filosofia no Instituto Agostiniano de Filosofia de Franca, São Paulo, Brasil. E-mail: matheus-s-castro@hotmail.com

2 Doutorando pelo Programa de Pós-Graduação em Ciências Sociais da UNESP Araraquara. Especialista em Ensino de Sociologia no Ensino Médio pela UFSJ. Mestre, bacharel e licenciado em Ciências Sociais da UNESP Araraquara. Editor chefe da revista Cadernos de Campos do Programa de Pós-Graduação em Ciências Sociais da UNESP Araraquara. 


\title{
THE USE OF PRODUCT DESIGN AS AN ENTREPRENEURIAL FORM OF TEACHING-LEARNING: A POSSIBLE PRACTICE?
}

\begin{abstract}
In an attempt to overcome exclusionary educational models and with teacher-centered teaching and learning processes, the beginning of the 21 st century saw the emergence of entrepreneurial pedagogy, which aims at training students concerned with society and the community in which they are inserted. As a way to awaken the entrepreneurial skills of students, especially high school students, teaching product design can lead students to reflect on the environment in which they live so that they can map problems and seek innovative solutions. The objective of this research is to present some product design methods and how they can be adopted for the development of entrepreneurial teaching-learning. For this, the present article starts from an exploratory research built from the interrelationship between entrepreneurial education, starting from product design, and its possibilities for high school in the sense of developing students' skills and competences. To this end, we will present the Common National Curricular Base (BNCC) for high school in the area of Aplied Human and Social Sciences and also the common Cognitive Axes of the Reference Matrices in force for the National High School Examination (ENEM). Next, we will present three product design methods: Product Development Process, Agile Project Management and Design Thinking. Finally, we will relate product design tools and their potential to meet the skills and competences expected from high school students.
\end{abstract}

Keywords: product design, entrepreneurship, entrepreneurial pedagogy, teaching.

\section{INTRODUÇÃO}

Durante muitos anos a educação foi marcada pela exclusão pois era privilégio somente de alguma pessoas, havendo a ausência de políticas educacionais efetivas em sua democratização (GENTILI, 2009). Além disso, sempre se caracterizou pela relação hierarquizada e de poder entre alunos e professores (NAGAI; IZEKI, 2013). Tudo isso levou os educadores a buscarem meios de mudar o cenário da educação. Com o tempo, diferentes abordagens de ensino foram adotadas pelas escolas, como a tradicional, a comportamentalista, a humanista, a cognitivista e a sociocultural, apresentando, cada uma delas, um foco diferente para o papel do aluno, do professor e do processo de ensino-aprendizagem (SANTOS, 2005).

$\mathrm{Na}$ abordagem sociocultural, ainda segundo Santos (2005), a educação não se restringe ao processo formal realizado nas escolas, mas sim a um processo que está inserido na sociedade, desenvolvendo a reflexão criativa, comprometida com a sociedade e sua cultura, posicionando o aluno e o professor como sujeitos do ato de conhecimento. Essa visão se aproxima à de Luckesi (2011), que afirma que a aprendizagem é um processo transformador do educando em suas relaçôes consigo, com o outro e com o mundo, ampliando a consciência de seu lugar no mundo e seu papel agente e crítico na construção de seu destino.

Dolabela (2003) indica que, no início do século XXI, a pedagogia empreendedora apresentou-se como uma estratégia didática para desenvolver as habilidades empreendedoras de alunos da educaçáo básica, possuindo uma preocupação social. A sua principal finalidade seria fortalecer os valores 
empreendedores na sociedade. Dolabela (2000) destaca a importância em despertar habilidades empreendedoras nos alunos, assim como o desenvolvimento de estratégias didáticas e pedagógicas para o ensino empreendedor.

Liberato (2007), apresenta o empreendedorismo como algo muito além de criar e gerir empresas. Ele destaca que empreendedorismo está ligado à realização do indivíduo por meio da inquietude, da ousadia e da proatividade, buscando um crescimento pessoal e coletivo, além do desenvolvimento da capacidade intelectual para investigar e solucionar problemas por uma iniciativa inovadora. Dolabela (2004), propóe que a pedagogia empreendedora comece a partir dos sonhos ou do contexto social do aluno, elementos importantes para que o próprio aluno seja sujeito em sua formação.

A proposta da inserção do empreendedorismo nos currículos escolares é criticada por alguns como um componente de conhecimentos instrumentais e ligados ao mundo dos negócios, à mentalidade corporativa. É verdade que o empreendedorismo agrega um conjunto de preocupações pragmáticas, algumas vezes com a geraçáo de um produto ao final de um processo desenvolvido, mas é fundamental ressaltar que tal processo está ligada a uma formação de alunos que assumam um papel crítico e criativo em sua vida social, elementos estes importantes para todo o sistema educacional e para a inserção na vida cidadã e no mercado de trabalho.

Como mencionado, o desenvolvimento de habilidades empreendedoras pode ser utilizado em toda a educação básica, mas elas se fazem necessárias principalmente no ensino médio, período em que os alunos estáo vivendo um grande momento de inquietaçáo e questionamentos quanto ao seu futuro profissional, sobre qual carreira seguir e o que fazer para buscar um meio de renda (LIBERATO, 2007). O ensino médio é o momento final da formação básica, imediatamente anterior à inserção no mercado de trabalho e na vida cidadá, além da maioridade frente à sociedade.

Uma forma de despertar e desenvolver as habilidades empreendedoras desses alunos no ensino médio é por meio do ensino de design de produtos. Design de produtos, ou desenvolvimento de produtos, é o conjunto de atividades desenvolvidas com o objetivo de se chegar às especificaçóes de um projeto que resultará na criação de um produto, serviço, ideia ou conceito (ROZENFELD et. al., 2006).

Reginaldo (2015, apud CROSS, 1990), destaca que o design pode ser utilizado na educação para desenvolver as capacidades dos alunos na resolução de problemas, devido a sua abordagem de problemas reais. Reginaldo (2015) destaca ainda que o ensino de design pode ser utilizado para se trabalhar de forma interdisciplinar, desafio constante da educação.

O ensino do design pode ser considerado como um meio para o ensino do empreendedorismo, pois ele pode ser utilizado para a criação e/ou desenvolvimento de produtos, serviços e soluçóes inovadoras, ou voltado para a necessidade da comunidade local ou para a resolução de problemas cotidianos (ROZENFELD et al., 2006; BROWN, 2010, AMARAL et al., 2011). Na pesquisa desenvolvida foram 
abordados os seguintes métodos de design de produtos: Processo de Desenvolvimento de Produtos, Gestão Ágil de Projetos e Design Thinking.

Sendo assim, a questáo que norteou a pesquisa foi: De que forma esses métodos de design de produtos se relacionam com o desenvolvimento de habilidades e competências no ensino médio?

Dessa forma, o objetivo da pesquisa foi presentar alguns métodos de design de produtos e indicar como eles podem ser adotados para o desenvolvimento do ensino-aprendizagem empreendedor no ensino médio.

A pesquisa se justificou pelo fato de apresentar alguns métodos de design de produtos com potencialidades de despertar habilidades e competências fundamentais nos alunos do ensino médio, por meio de atividades práticas e voltadas à resolução de problemas reais da comunidade na qual o aluno está inserido.

Os documentos analisados foram a Base Nacional Comum Curricular (BNCC) para o ensino médio na área de Ciências Humanas e Sociais Aplicadas e os Eixos Cognitivos Comuns das Matrizes de Referência vigentes para o Exame Nacional do Ensino Médio (ENEM). A BNCC organiza a educação básica no país e lista habilidades e competências a serem desenvolvidas pelos alunos, sendo o foco pela área de Ciências Humanas e Sociais Aplicadas justificada na medida em que o empreendedorismo está no campo das Ciências Sociais Aplicadas. Por sua vez, o ENEM é um exame avaliativo do ensino médio no país, sendo os Eixos Cognitivos uma enumeração de habilidades e competências esperadas dos alunos que concluem o ensino médio.

A hipótese previamente foi a de que o ensino de design de produtos apresenta potencialidades para desenvolver um processo de ensino-aprendizagem empreendedor e que, com isso, os alunos poderiam pensar de forma ativa e inovadora os problemas de sua comunidade através do desenvolvimento de habilidades e competências fundamentais à vida social.

\section{METODOLOGIA}

A pesquisa é um conjunto de açôes, que tem por objetivo propor a solução de um determinado problema, na qual sáo utilizados procedimentos racionais e sistemáticos para a sua construção, ou seja, a pesquisa é realizada quando se tem um problema e não se tem informaçóes para solucioná-lo (SILVA; MENEZES, 2001).

A metodologia tem por finalidade conduzir a pesquisa para que os resultados obtidos sejam satisfatórios, baseados em um planejamento cuidadoso e fundado em conhecimentos já existentes (SILVA; MENEZES, 2001). Para a realização dessa pesquisa foi adotada a abordagem qualitativa por meio da pesquisa bibliográfica e documental.

Silva e Menezes (2001) descrevem que a pesquisa qualitativa é produzida sem a necessidade de métodos estatísticos, onde o pesquisador é instrumento-chave para a coleta dos dados, realizando a análise dos dados de forma indutiva. A pesquisa 
bibliográfica é elaborada a partir de material já publicado em livros, revistas, periódicos e sites, enquanto a documental recorre a normativas oficiais como dados (GIL, 1991).

Nessa pesquisa, o levantamento da bibliográfica foi realizado para descrever alguns métodos de design de produtos e serviços: Processo de Desenvolvimento de Produtos, Gestão Ágil de Projetos e Design Thinking e algumas ferramentas aplicadas na sua elaboração. Por sua vez, os documentos analisados, a Base Nacional Comum Curricular (BNCC) para o ensino médio na área de Ciências Humanas e Sociais Aplicadas, além dos Eixos Cognitivos Comuns das Matrizes de Referência vigentes para o Exame Nacional do Ensino Médio (ENEM).

\section{DESENVOLVIMENTO DA PESQUISA}

\subsection{A BNCC e o ENEM: despertar habilidades e competências nos discentes do ensino médio}

O documento Matriz de Referências ENEM visa esclarecer os parâmetros utilizados na avaliação dos estudantes do ensino médio. Além de apresentar uma série de conteúdo específicos, divididos em quatro áreas do conhecimento (Linguagens, Códigos e suas Tecnologias; Matemática e suas Tecnologias; Ciências da Natureza e suas Tecnologias; e Ciências Humanas e suas Tecnologias), traz também habilidades e competências que são esperadas dos discentes (BRASIL, 2011). Ou seja, para uma adequada demonstração de conteúdo específicos, a avaliação demanda que os alunos estejam aptos a mobilizar e aplicar habilidades e competências que acumularam durante seu processo de escolarização na resolução das questóes.

Dentro dos Eixos Cognitivos, que são comuns a todas as áreas do conhecimento, são enumerados cinco: Dominar linguagens (DL), Compreender fenômenos (CF), Enfrentar situações-problema (SP), Construir argumentação (CA) e Elaborar propostas (EP) (BRASIL, 2011). O eixo DL está ligado com habilidades comunicativas de compreender e expressar a sociedade vivida e o conjunto de seus conhecimentos, juntamente à compreensão da possibilidade de fazê-lo em outras línguas (limitada ao espanhol e ao inglês) (BRASIL, 2011). O eixo CF tem relação com a compreensão não só dos fenômenos naturais, mas também dos sociais em suas pluralidades de produção e expressão (histórico-geográficas, tecnológicas e artísticas) (BRASIL, 2011). Os eixos SP, CA e EP tratam da compreensão e interpretação de dados e informaçóes relevantes ao enfrentamento de uma situação-problema de modo propositivo, de modo que as decisóes tomadas sejam fundadas em princípios solidários e empáticos em observância à pluralidade sociocultural (BRASIL, 2011).

Os cinco eixos visam um aluno que possa localizar-se na vida social, assim como compreender que a sociedade em que se insere, junto a seu conjunto de conhecimentos e maneiras de organização e narrativas sobre o mundo, representam uma das muitas possibilidades de viver coletivamente. Dessa forma, sentimentos empáticos e solidários permitem compreender a riqueza que há na heterogeneidade 
entre as sociedades e dos diferentes grupos que compóem uma mesma sociedade. Essas habilidades são desenvolvidas na medida em que o aluno aprende os diferentes conteúdos escolares nos anos de formação.

Por outro lado, é esperado que o aluno tenha capacidades críticas em relação à sua sociedade, mobilizando seus diversos conhecimentos para analisar situaçôesproblema e para que possa fazer proposiçóes práticas de benefício coletivo. Esse aluno precisa então desenvolver capacidades de trabalhar individualmente e coletivamente, mobilizando ferramentais adquiridos nos conteúdos escolares e utilizando as habilidades desenvolvidas durante a fase da escolarização que, muito além dos muros escolares e sequências avaliativas, lidam com desafios da vida social.

A BNCC é um documento normativo que visa assegurar o direito de aprendizagem e desenvolvimento dos estudantes do ensino básico, baseando-se nos princípios "éticos, políticos e estéticos que visam à formação humana integral e à construção de uma sociedade justa, democrática e inclusiva, como fundamentado nas Diretrizes Curriculares Nacionais da Educação Básica (DCN)" (BRASIL, 2017, p. 7). Fundamental para este artigo, o documento define competência enquanto "mobilização de conhecimentos (conceitos e procedimentos), habilidades (práticas, cognitivas e socioemocionais), atitudes e valores para resolver demandas complexas da vida cotidiana, do pleno exercício da cidadania e do mundo do trabalho" (BRASIL, 2017, p.8).

É possível notar que a BNCC não se limita a uma normatização sobre conteúdos escolares que devem ser ensinados e aprendidos. Na verdade, eles fazem parte da leitura, interpretação e dizer do mundo social vivido. $O$ documento demonstra que é esperado que, ao final do período de escolarização básica, o indivíduo seja capaz de se inserir na plena cidadania e no mundo do trabalho, sendo imperioso que tenha desenvolvidas as competências necessárias para tomar decisóes de maneira crítica e ligada às demandas da vida em sociedade. Assim, é possível notar a tentativa de formar um sujeito crítico, autônomo, coletivo e criativo frente a sua vida.

No tocante às competências essenciais, o documento enfatiza a necessidade de que o estudante seja capaz de conhecer a si e ao outro em uma perspectiva histórica da sociedade em que vive, junto ao respeito à diferença e às diversas manifestações desta, seja cultural, estética/artística, emocional, identitária, de saberes e de experiências vivenciadas, reconhecendo as potencialidades e evitando preconceitos de qualquer tipo (BRASIL, 2017). Há também as competências ligadas à comunicação e à informação, sendo esperado que os estudantes sejam capazes de buscar, selecionar e interpretar informaçôes confiáveis baseadas nos valores éticos, democráticos e inclusivos da vida social, aproveitando-se das diferentes linguagens possíveis para expressar-se e compartilhar entendimentos mútuos (BRASIL, 2017).

O documento trata da mudança dos alunos do nível fundamental para o médio, afirmando que "o desenvolvimento das capacidades de observação, memória e abstração permite percepções mais acuradas da realidade e raciocínios mais complexos", favorecendo "processos de simbolizaçáo e de abstração" (BRASIL, 
2017, p. 547). Entendendo que, nessa fase, os jovens se inserem de forma mais amadurecida na vida social, é esperado que busquem protagonismo sobre suas decisôes com base na empatia e na ética (cidadã e ecocidadã), mobilizando na vida social todo o ferramental material, como as tecnologias digitais, e simbólico, como a arte, as linguagens e a cultura (BRASIL, 2017).

A maturidade dos jovens do ensino médio é apresentada paralelamente ao adensamento de seus conhecimentos curriculares. Dessa forma, características como a curiosidade e a criatividade, baseadas na análise e seleção de informaçôes e dados relevantes, permitem que o jovem busque açôes cooperativas, dialógicas, éticas e flexíveis para resolver conflitos e também soluçóes inovadoras para as comunidades em que convive (BRASIL, 2017).

Em um recorte por áreas do conhecimento, o documento indica que "a área de Ciências Humanas e Sociais Aplicadas tem ainda o grande desafio de desenvolver a capacidade dos estudantes de estabelecer diálogos entre indivíduos, grupos sociais e cidadãos de diversas nacionalidades, saberes e culturas distintas" (BRASIL, 2017, p. 548). Assim, essa área é fundamental na transposição entre o indivíduo aluno e o indivíduo cidadáo, uma vez que os conteúdos da área são de grande importância para uma compreensáo crítica do estar no mundo e que permitem a apreensáo e aplicação de elementos éticos na convivência e na tomada de decisóes. Ou seja, o desenvolvimento dos conteúdos nessa área é simultâneo ao desenvolvimento das habilidades fundamentais para a inserção na maioridade, na plena cidadania e no mercado de trabalho. Essas observaçôes aparecem mais bem relacionadas no seguinte trecho:

Todavia, a identificação de uma questão, a realização de recortes e a interpretação de fenômenos demandam uma organização lógica, coerente e crítica para a elaboração das hipóteses e para a construção da argumentação em torno das categorias selecionadas. Nas Ciências Humanas e Sociais Aplicadas, analisar, relacionar, comparar e compreender contextos e identidades são condiçôes para conhecer, problematizar, criticar e tomar posiçôes (BRASIL, 2017, p. 548-49).

A BNCC e as Matrizes do ENEM acompanham preocupaçóes constantes da área educacional quanto à necessidade de envolver os alunos de maneira protagonista nos processos de aprendizagem, mas transcendendo a ideia de conteúdos escolares e, a partir da apuraçáo do senso crítico, colaborando para que os alunos vejam esses conhecimentos nas vivências que experienciam (PINTO et al., 2012). Para Behrens (1999), o desafio escolar é criar nos jovens, capacidades de trabalho em grupo e tomada de decisóes de forma autônoma, crítica e solidária na partilha de conhecimentos, o que demanda mais do que práticas pedagógicas baseadas na mera reprodução dos conteúdos escolares desenvolvidos. Apesar dessas inquietações importantes, há um senso comum, inclusive entre professores, de que os jovens estão cada vez menos interessados nos estudos e frustrados quanto às possibilidades de seu protagonismo nos processos sociais, dificultando as relaçôes entre professores e alunos e prejudicando os processos de ensino-aprendizagem (SANTOS; SOARES, 2011). 
Tendo em vista a área de Ciências Humanas e Sociais Aplicadas e buscando meios para que o aluno do ensino médio possa desenvolver habilidades e competências essenciais para sua inserçáo na plena cidadania e no mundo do trabalho, apresentamos na sequência alguns princípios do design de produtos e serviços, ramo de conhecimentos do empreendedorismo que integra a área em questão, buscando encontrar suas potencialidades educacionais. São três os métodos de design de produtos que apresentaremos: Processo de Desenvolvimento de Produtos, Gestão Ấgil de Projetos e Design Thinking.

\subsection{Processo de Desenvolvimento de Produtos (PDP)}

Agostinetto (2006) apresenta o Processo de Desenvolvimento de Produtos (PDP) como um processo com características favoráveis para a criação e inovação, sendo ele uma imensa fonte de conhecimento por não apresentar atividades repetitivas, o que permite uma maior possibilidade de aprendizado. Browning at al. (2006) e Jun e Suh (2008) acrescentam ainda que o PDP possui características como criatividade e inovação, podendo ser considerado interdisciplinar, dinâmico, iterativo e não linear.

O PDP pode ser definido como um conjunto de atividades sistemáticas para a identificaçáa do mercado e das necessidades dos consumidores até o momento da venda, envolvendo produto, processo, pessoas e organização (PUGH, 1990). Já Clark e Fujimoto (1991) apresentam o PDP como um processo em que a organização transforma dados do mercado em informaçóes de valor para a produçáo comercial.

Associando os conceitos anteriores, Rozenfeld et al. (2006) define o PDP como um conjunto de atividades que, a partir da análise de necessidades do mercado, a disponibilidade de tecnologia e a estratégia competitiva, tem por objetivo especificar o projeto de um produto e seu processo de produção para que a manufatura seja capaz de produzi-lo.

Para o PDP, existem vários modelos pelos quais ele pode ser representado. Nesse trabalho será apresentado e detalhado o modelo de Rozenfeld et al. (2006), por ser considerado o modelo mais completo e o mais difundido no Brasil. A Figura 1 apresenta a ilustraçáo desse modelo. 
Figura 1. Modelo de Processo de Desenvolvimento de Produto

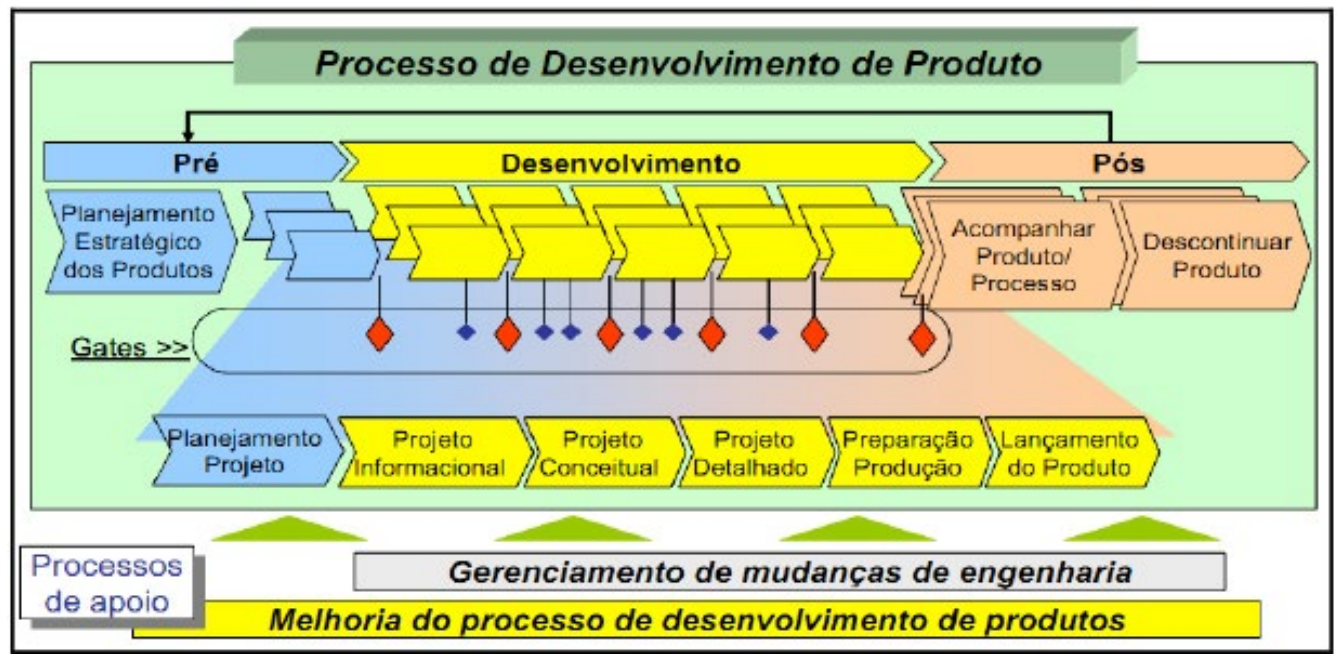

Fonte: ROZENFELD et al., 2006, p. 44

O pré-desenvolvimento é o processo de tradução do planejamento estratégico da empresa no planejamento estratégico do produto ou serviço. Nessa macrofase estáo as atividades de definiçáo do projeto de desenvolvimento, delimitaçóes de recursos, levantamento de tendências dos consumidores, de tecnologia e mercadológicas.

O desenvolvimento inicia-se com a definição do portfólio de produtos e o planejamento dos projetos. Nela sáo definidas as especificaçóes-meta do produto (um conjunto de informações sobre o produto a ser desenvolvido), com a transformação dos requisitos do cliente em requisitos do produto, a conceituação e a estruturação do produto, a homologação do produto e o seu lançamento.

O pós-desenvolvimento é caracterizado pelo acompanhamento e descontinuação do produto no mercado. Nessa macrofase é realizada a documentação do pós-venda, onde são elencadas as melhorias a serem feitas no produto. Todas as informaçóes geradas aqui são usadas como referências para o desenvolvimento de novos produtos.

O desenvolvimento de produtos pode ser classificado por diversos critérios, baseados no grau de mudança dos projetos a serem realizados com base nos anteriores (ROZENFELD et al., 2006). A Figura 2 apresenta a classificaçáo desses projetos de desenvolvimento. 
Figura 2. Classificação de projetos de desenvolvimento baseados na inovação

\begin{tabular}{|c|c|c|c|c|c|}
\hline \multirow{5}{*}{ 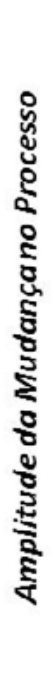 } & \multicolumn{5}{|c|}{ Amplitude da Mudança de Projeto } \\
\hline & $\begin{array}{l}\text { Pesquisa e } \\
\text { Desenvolvimento } \\
\text { Avançado }\end{array}$ & $\begin{array}{l}\text { Conceito } \\
\text { Novo }\end{array}$ & $\begin{array}{l}\text { Próxima } \\
\text { Geração }\end{array}$ & $\begin{array}{l}\text { Adiçăo de } \\
\text { Produto } \\
\text { A Familia }\end{array}$ & $\begin{array}{l}\text { Incrementais e } \\
\text { Derivados }\end{array}$ \\
\hline & $\begin{array}{l}\text { Conceito } \\
\text { Novo }\end{array}$ & $\begin{array}{l}\text { Inovações } \\
\text { Radicals }\end{array}$ & & & \\
\hline & $\begin{array}{l}\text { Próxima } \\
\text { Geração } \\
\text { Melhoria }\end{array}$ & & $\begin{array}{l}\text { Próxima Geração ou } \\
\text { Plataforma }\end{array}$ & & \\
\hline & $\begin{array}{l}\text { em um } \\
\text { Departamento } \\
\text { Ajustes e } \\
\text { Mudanças } \\
\text { Incrementais }\end{array}$ & & $\begin{array}{l}\text { Alianças ou } \\
\text { Projetos de Parceria }\end{array}$ & $\begin{array}{l}\text { Projetos } \\
\text { Incrementais e } \\
\text { Derivados }\end{array}$ & \\
\hline
\end{tabular}

Fonte: ROZENFELF et al., 2006, p. 8

Nessa classificação, os projetos radicais são os que envolvem grandes inovaçóes e mudanças no projeto do produto. Já os projetos de próxima geração ou plataforma apresentam uma mudança significativa no projeto, mas sem a inclusão de novas tecnologias e materiais. Finalmente, os projetos incrementais e derivados apresentam poucas mudanças em relação aos projetos já existentes, havendo apenas algumas mudanças como em relação ao custo.

No PDP, segundo Rozenfelf et al. (2006), as fases realizadas para a sua elaboração podem variar de acordo com a classificação apresentada, pois quanto mais inovador é o produto, mais detalhado deve ser o PDP, para que seja garantida a realização e validação de todas as variáveis que podem resultar no sucesso do projeto. Quanto menos inovador for o PDP, mais as fases podem ser encurtadas ou mescladas, pois grande parte das informaçôes já será conhecida pela equipe.

\subsection{Gerenciamento Ágil de Projetos (GAP)}

A disciplina de gestão de projetos, segundo Crawford, Pollack e England (2006), pode ser aplicada em diferentes segmentos. O gerenciamento Ágil de Projetos surgiu como uma abordagem alternativa ao modelo tradicional de projetos, como, por exemplo, o PMBOK, que tem como objetivo o desenvolvimento de produtos inovadores em ambientes dinâmicos (SMITH, 2007; CHIN, 2004; HIGHSMITH, 2004). 
Para Highsmith (2004), o Gerenciamento Ágil de Projetos (GAP) pode ser considerado como um conjunto de princípios, valores e práticas que auxiliam a equipe de projetos a produtos e serviços em um ambiente de projetos desafiador. Augustine (2005) destaca ainda que o GAP deve ter um time de projeto hábil capaz e de realizar entregas rápidas e confiantes, por meio da integração dos clientes em um processo contínuo de aprendizagens.

Segundo Chin (2004) o GAP requer uma menor quantidade de padróes e de pessoas envolvidas no projeto. $\mathrm{O}$ autor ressalta ainda que devido às grandes incertezas e mudanças que predominam o ambiente dos projetos inovadores, a existência de técnicas simplificadas e o envolvimento da equipe se adequam melhor a esses ambientes.

Buscando propor uma representação para a aplicação do GAP, Highsmith (2004) propóe seis princípios que estão relacionados à entrega do produto, à liderança e à colaboração, devendo haver uma intensa colaboração e interação entre todos os membros do projeto. Essa representação é apresentada na Figura 3.

Figura 3. Princípios do Gerenciamento Ágil de Projetos

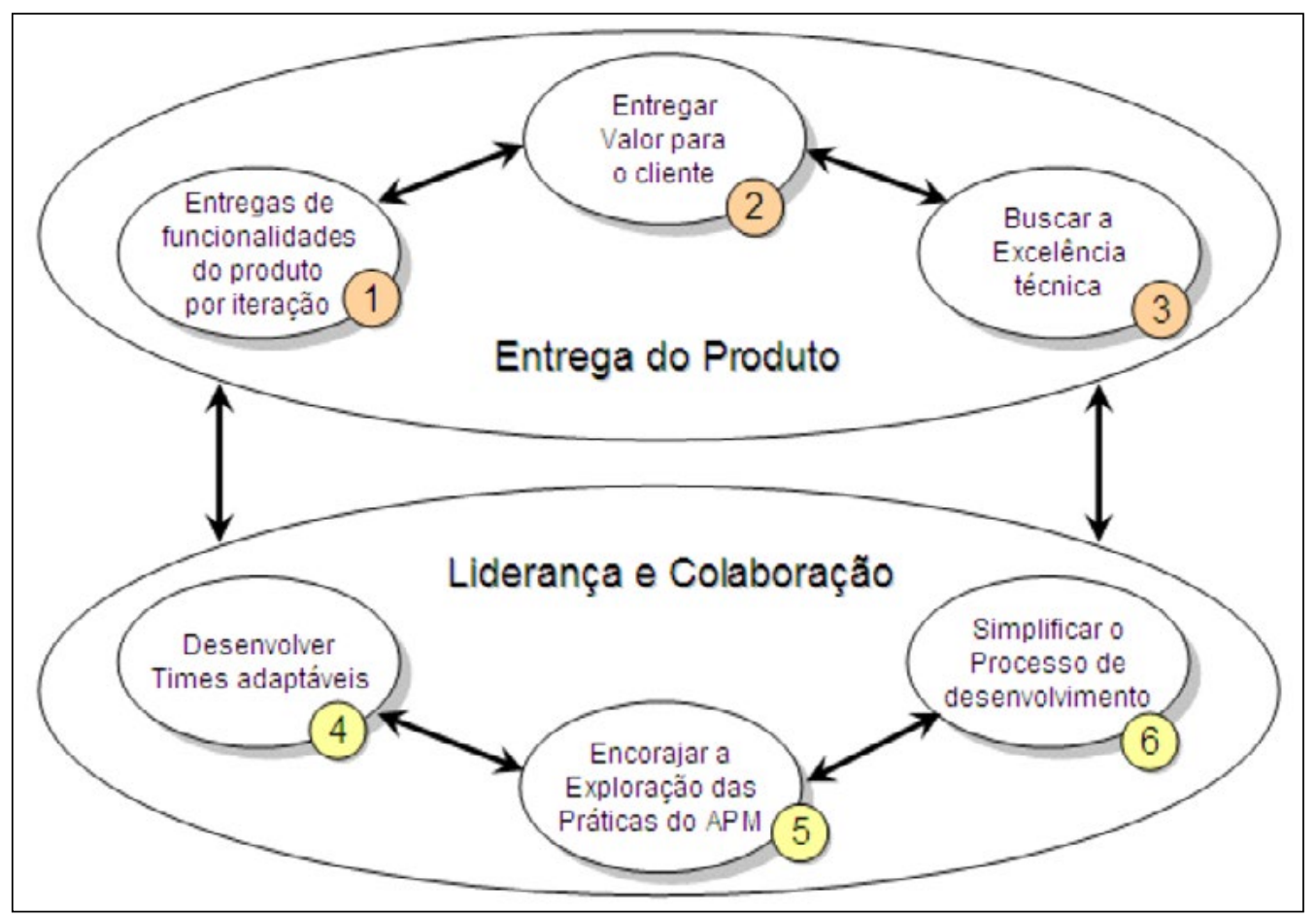

Fonte: HIGHSMITH, 2004, p. 28

No GAP, a realização de interações é fundamental para que se possa produzir um resultado do produto em um determinado período, podendo esse resultado ser melhorado posteriormente (HIGHSMITH, 2004). 
Há na literatura a proposição de um modelo para o gerenciamento de projetos tidos como ágeis. A Figura 4 sintetiza as concepçôes de Highsmith (2004) para o gerenciamento de projetos, que o divide em cinco etapas:

- Visão: tem por objetivo determinar a visão do produto/serviço e o escopo do projeto, com a definição da equipe;

- Especulação: visa planejar o projeto de acordo com a visão preliminar e refinar a visão do produto/serviço a partir da identificaçáo de requisitos;

- Exploração: realizar a execuçáo das entregas, gerenciamento da carga de trabalho, promover a auto-organização e a autodisciplina da equipe com a interaçáo da equipe como um todo com o projeto com o cliente;

- Adaptação: destinada a rever os resultados da fase anterior, analisar o progresso do projeto e o desenvolvimento da equipe;

- Encerramento: fase final, que objetiva transferir os conhecimentos adquiridos no projeto.

Figura 4. Modelo de Gerenciamento Ágil de Projetos

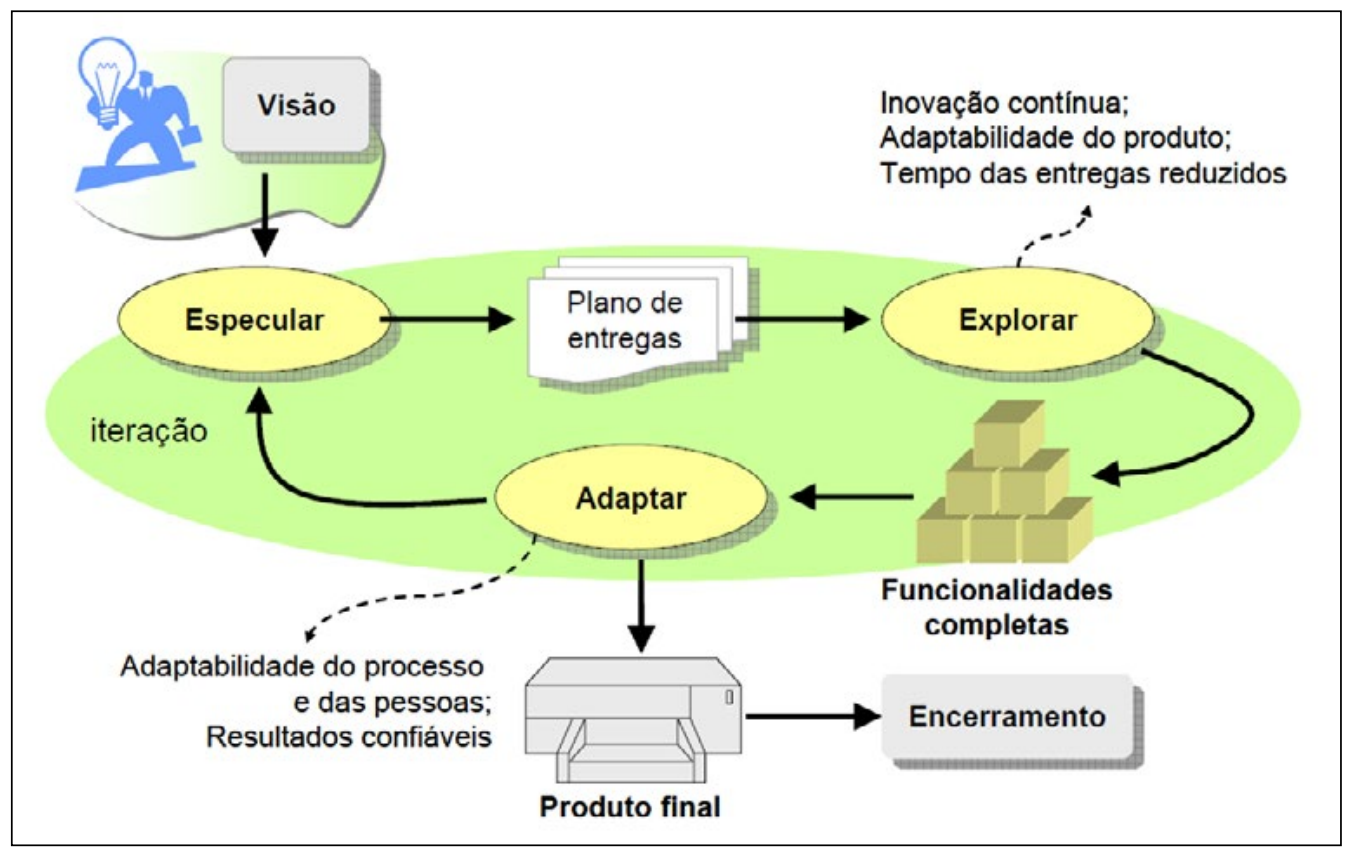

Fonte: HIGHSMITH, 2004, p. 81

\subsection{Design Thinking (DT)}

Woudhuysen (2011) destaca que, após a Guerra Fria, o papel dos designers não era mais apenas o de atender ao que os líderes corporativos queriam, mas sim as 
necessidades o atendimento das necessidades dos mercados, movimento conhecido por demanda bottom up.

Dessa forma, surge o Design Thinking, caracterizado como a busca da compreensáo de fenômenos a partir da formulação de perguntas a serem respondidas por meio de informaçóes coletadas in loco, fundamentando a realizaçáo de projetos com foco nas necessidades das pessoas (BROWN, 2010; SANDERS, 2001).

O processo de Design Thinking apresenta, segundo Vianna (et al., 2012) três fases fundamentais: imersão, ideação e prototipação. Essas fases têm por objetivo questionar os problemas e as ideias geradas e obter as respostas. A Figura 5 apresenta esses elementos.

Figura 5. Fases do processo de Desing Thinking

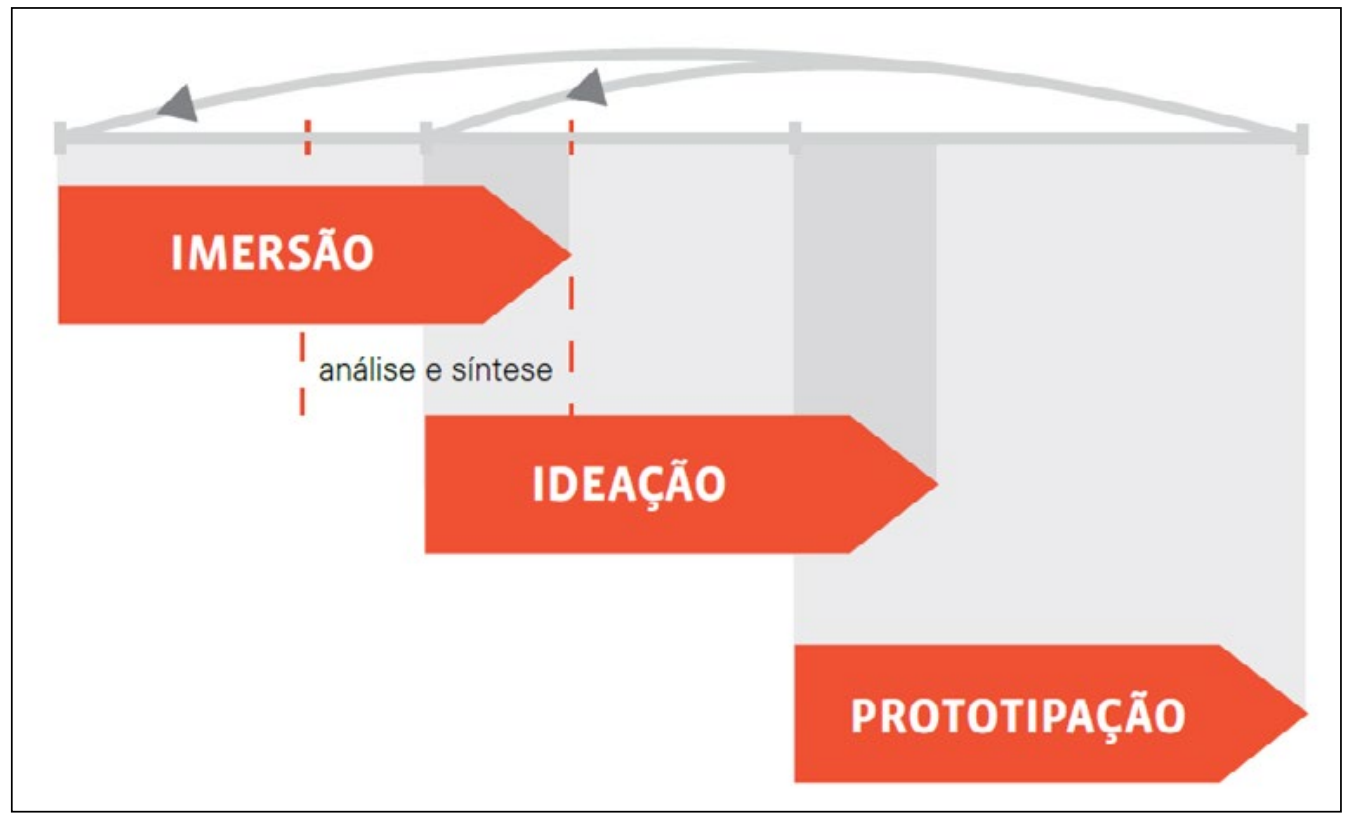

Fonte: VIANNA et al., 2012, p. 18

A fase de imersão busca a aproximação do contexto do projeto para que haja o entendimento do problema inicial, tanto do ponto de vista da empresa quanto do ponto de vista do cliente final, além da identificação de necessidades e oportunidades que proporcionam a geração de soluçóes na fase de ideaçáo.

$\mathrm{Na}$ fase de ideação, o objetivo é gerar ideias inovadoras para o projeto por meio de várias ferramentas para que novas soluçóes sejam criadas. Nessa fase é essencial que a equipe seja formada por pessoas de diversas áreas de atuação, formando equipes multidisciplinares para que haja a contribuição de diferentes perspectivas, $o$ que possibilita um resultado mais assertivo. 
Por fim, na fase de prototipaçáo, ocorre a validaçáo das ideias geradas por meio de protótipos criados para proporcionar a validaçâo do que foi desenvolvido, o que permite reduzir as incertezas do projeto e antecipar eventuais seus possíveis problemas.

A IDEO, empresa de design, consultoria e inovação, lançou em 2012 um toolkit intitulado "Design Thinking para Educadores", que apresenta uma adaptaçáo do Design Thinking para a aplicação no cotidiano docente. O IDEO (2012) possui cinco fases fundamentais: descoberta, interpretação, ideação, experimentação e evolução. Nessas fases, os problemas são questionados, as ideias geradas e as respostas obtidas para construir soluçóes. Essas fases são apresentadas na Figura 6.

Figura 6. Processos do Design Thinking

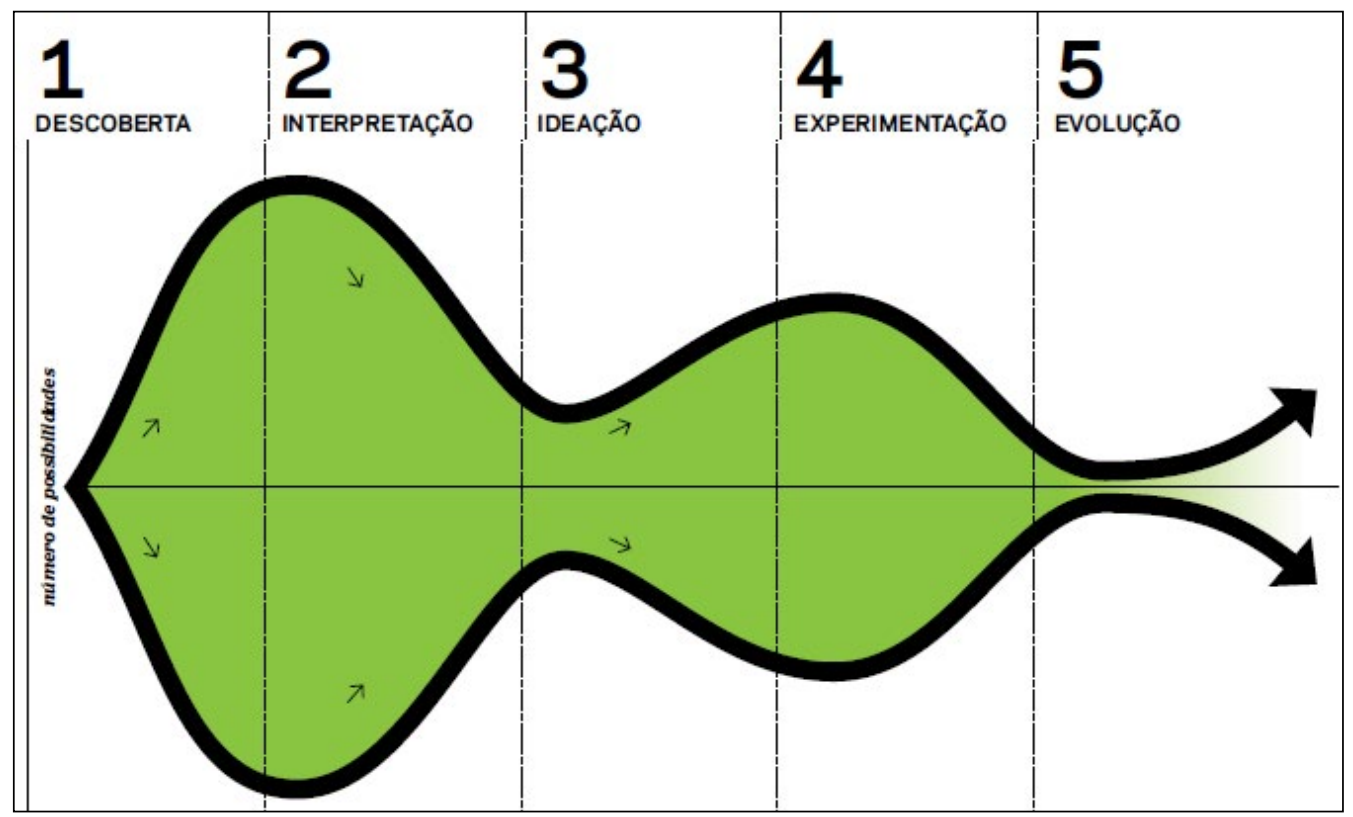

Fonte: adaptado de IDEO, 2012, p. 15

O objetivo do processo do IDEO (2012) é o mesmo apresentado por Vianna (2012), mas dividido em várias etapas para que a equipe siga os passos para o seu desenvolvimento. Durante as fases, o número de possibilidades geradas aumenta e diminui. O aumento é provocado pelo leque de opçôes que se tem de ideias e que, com as discussóes, vão sendo selecionadas e refinadas para algo mais preciso e palpável.

\subsection{Ferramentas do design de produtos aplicáveis à educaçáo}

Para a elaboração e realização dos métodos de design apresentados neste artigo, diversas atividades são realizadas nas fases mencionadas. Essas atividades são 
realizadas com o auxílio de diversas ferramentas que ajudam no maior sucesso do processo.

O desenvolvimento de um produto se dá a partir do planejamento, que é utilizado para que sejam avaliadas as forças e fraquezas, bem como as tendências do mercado, para formular posteriormente o projeto. Ele também é utilizado para que seja criada uma visão do futuro, o que auxilia na tomada de decisóes (MINTZBERG, 2006).

Outra ferramenta essencial para a definição do produto é a Análise SWOT, composta por uma avaliação das Strengths (Forças), Weaknesses (Franquezas), Opportunities (Oportunidades) e Threats (Ameaças). Ela é utilizada para o suporte estratégico e para estudar os fatores críticos internos e externos em relação ao que está sendo desenvolvido (LOBATO, 2002).

A pesquisa de mercado tem por objetivo captar as necessidades do usuário final por meio do monitoramento dos seus hábitos e atitudes (DOLAN, 1993). A pesquisa de mercado pode ser utilizada para prever demandas de produto, determinar os concorrentes, gerenciar o portfólio de produtos, analisar oportunidades de mercado, testar o conceito de produtos, entre outros.

Dentre as técnicas utilizadas para a criação e avaliação de ideias, duas são muito utilizadas: brainstorm e workshop. O brainstorm é utilizado para estimular a geração de ideias em um curto espaço de tempo e é realizado com um grupo de pessoas conduzido por um moderador. Já o workshop é caracterizado como um encontro com uma série de atividades em grupo que tem o objetivo estimular a criatividade e colaboraçáo, fomentando a criação de soluçóes inovadoras. Participam desse workshop pessoas que estejam envolvidas com as soluçôes que estáo sendo desenvolvidas (VIANNA et al., 2012).

Para determinar se um produto/projeto é viável, é preciso realizar a sua viabilidade econômica para que sejam definidos os indicadores financeiros por meio da realização do retorno do investimento, valor presente líquido, taxa interna de retorno, payback, fluxo de caixa, entre outros (ROZENFELD et al, 2006).

$\mathrm{O}$ método PERT/CPM é utilizado para determinar precedências entre as atividades em um projeto. Essas precedências são utilizadas parar calcular o tempo total gasto no projeto, bem como as atividades que não podem atrasar para que se cumpra o prazo estipulado. Por meio dele também podemos determinar a alocaçáo de recursos e análise de custos (FERNANDES; GODINHO FILHO, 2010).

Por fim, a prototipação é utilizada para verificar se a ideia é tangível, passando o produto do abstrato para o físico, representando a realidade, propiciando a sua validação (VIANNA et al., 2012).

\section{ANÁLISE E DISCUSSÃO DOS RESULTADOS}

Os métodos de design de produtos apresentam potencialidades educacionais no sentido de desenvolver nos alunos habilidades e competências fundamentais à 
vida social. O PDP demanda situações dinâmicas e com interlocuçáo de diferentes atores e conhecimentos no mapeamento de situaçóes-problema para que, a partir de uma imersão nas necessidades experienciadas por uma comunidade, possam ser elencados os recursos disponíveis e as etapas da produção de uma solução inovadora. Há então na necessidade da seleção de informaçóes e análise crítica delas quanto às demandas levantadas e recursos disponíveis para que então seja elaborado o projeto, o plano de ação coletiva na produção da solução. Os alunos, ao se depararem com uma situação-problema que demanda solução, poderiam organizar os trabalhos individuais e coletivos dentro das categorias de pré-desenvolvimento, desenvolvimento e pós-desenvolvimento de uma soluçáo inovadora, aprimorando habilidades e competências em suas tomadas de decisóes.

O GAP demanda necessariamente o trabalho coletivo. Assim, os valores éticos e empáticos são exercitados junto ao grupo de trabalho e ao público final que receberá a solução inovadora criada em equipe. O DT tem uma interface individual importante, enfatizando que o designer necessita das etapas de imersão, ideação e prototipaçáo. Nesse sentido, o indivíduo precisa inserir-se in loco de maneira empática e flexível para revisar criticamente a sua realidade vivenciada ou compreender outras realidades que venha a experienciar dentro de um universo de possibilidades. Com isso, ele é capaz de coletar e organizar informaçóes e dados relevantes para que possa sintetizar, em um produto, as soluçóes para uma situação-problema encontrada. Considerando o aluno, ele será capaz de relativizar suas experiências, compreender o seu estar no mundo e valorizar as demais formas de expressão individual e coletiva, possibilitando que ele dialogue de forma ética e empática para mapear situaçóes-problema e proponha soluçóes inovadoras e criativas.

Cross (1982 apud REGINALDO, 2015) identificou três características do design que podem ser aplicadas na educação: o desenvolvimento da capacidade dos alunos na resoluçáo de determinados problemas, pois sáo mais reais que os das ciências e humanidades; o desenvolvimento cognitivo pelas constantes atividades mentais e práticas; e desenvolvimento de habilidades do pensamento não verbal e comunicação.

As atividades de design podem ser consideradas como uma boa oportunidade para criar e promover as condiçóes necessárias para a construção do conhecimento na sala de aula por meio da manipulaçáo de objetos e pela interação com o ambiente (FONTOURA, 2002). Os métodos de design apresentados nesse trabalho podem ser aplicados para o desenvolvimento de vários tipos de produtos, além de permitirem o aumento da comunicaçáo, do entendimento dos fatos, do uso da língua, da análise dos dados, da compreensão da realidade e dos fenômenos sociais, de realizar raciocínios lógicos e sequenciais e de apresentar propostas de soluçóes e/ ou melhorias à comunidade.

A execução dessas ferramentas possibilita a formação empreendedora do aluno, pois por meio dela é possível que o aluno conheça a comunidade à sua volta e reflita sobre quais as suas necessidades, o que é possível fazer para torná-la melhor, 
como desenvolver produtos e serviços que ofertem uma maior qualidade de vida melhor, refletindo sobre as fraquezas e pontos fortes da comunidade. Ela possibilita ainda a socialização do aluno, pois é necessário que haja um trabalho em grupo no qual cada um é responsável pela sua função, sem deixar de pensar no coletivo, sendo que cada fase do desenvolvimento requer a integração de todas as áreas envolvidas.

As disciplinas curriculares dos alunos podem ser ensinadas ou empregadas na prática, já que para o desenvolvimento do produto o aluno precisa realizar a viabilidade do projeto, utilizando por exemplo os conceitos de matemática financeira, o emprego das regras gramaticais e ortográficas para a elaboração do planejamento estratégico, a prototipaçáo dos conceitos de artes plásticas para obter um produto de boa aparência e ergonômico ou uma soluçáo para o fortalecimento da comunidade. Além disso, como apontado por Reinaldo (2015), é uma forma de aprendizado interdisciplinar.

O ensino do design proporciona também ao aluno lidar com incertezas, pois estará inserido em um ambiente crítico e sujeito a tomadas de decisóes, além de tomar parte na resoluçáo de problemas. Esses fatores demandam do aluno a busca pelo conhecimento para resolver e solucionar essas incertezas e problemas, possibilitando que o aluno seja o próprio construtor do seu conhecimento junto com os outros alunos e professores, como destacado por Santos (2005) na abordagem sociocultural de ensino. Para Oliveira (2011) a autoaprendizagem estimulada na pedagogia empreendedora não diminui a ação do educador, mas aumenta a sua importância, pois o educador passa a ser o responsável por ampliar as referências e fontes de aprendizagem dos alunos, preparando um ambiente favorável para o aluno construir seu próprio saber empreendedor.

\section{CONCLUSÃO}

Os desafios da educação, em especial no que se refere à transposição dos conteúdos escolares para a vida social, são de amplo debate e não possuem um consenso quanto a uma forma inequívoca de resolução. Além disso, também é demandado que os conteúdos escolares tenham sentido nas experiências de vida dos alunos, nas suas relaçóes com o mundo com a expectativa de que os estudantes sejam capazes de mobilizar esses conhecimentos para agir de maneira crítica, autônoma, solidária, inovadora e ética. Isso se torna crítico no ensino médio na medida em que esse aluno está prestes a ingressar na plena cidadania e no mercado de trabalho.

Diferentes documentos oficiais de normatização e de avaliação do ensino médio, aqui tratadas a BNCC e as Matrizes do ENEM, indicam a preocupação de que o período de escolarização vá além da transmissão de conteúdos essenciais com validade científica produzidos por diferentes sociedades em diferentes períodos. Sensivelmente na área das Ciências Humanas e Sociais Aplicadas, é indicado que o aluno deve apreender os conteúdos curriculares, mas também desenvolver uma série de habilidades e competências de cunho individual e coletivo para entâo ser capaz de transpor os conteúdos curriculares para situaçôes de vida. 
O uso dos métodos de design pode proporcionar aos alunos uma forma ativa de aprendizado, pois com a adoção desses métodos eles podem ser capazes de criar produtos materiais e imateriais inovadores, gerar soluções para os problemas da comunidade e facilitar o processo de ensino-aprendizagem, pois ele foca na resoluçáo de problemas. Foi possível encontrar, na pesquisa desenvolvida, um amplo diálogo entre as habilidades necessárias para as chamadas práticas empreendedoras e habilidades demandadas naqueles documentos oficiais.

\section{REFERÊNCIAS}

AGOSTINETTO, J. S. Sistematizaçáo do processo de desenvolvimento de produtos, melhoria contínua e desempenho: o caso de uma empresa de autopeças. São Carlos, Dissertação de mestrado - Escola de Engenharia de São Carlos - USP, 2006.

AMARAL, D. C. et al. Gerenciamento ágil de projetos: aplicaçáo em produtos inovadores. São Paulo: Saraiva, 2011.

AUGUSTINE, S. Managing Agile Projects. Virginia: Prentice Hall PTR, 2005.

BEHRENS, M. A. A prática pedagógica e o desafio do paradigma emergente. Revista Brasileira de Estudos de Pedagogia, Brasília, v. 80, n. 196, p. 383-403, 1999.

BRASIL, Ministério da Educação. Matriz de Referência ENEM. Brasília: Instituto Nacional de Estudos e Pesquisas Educacionais Anísio Teixeira, 2011. Disponível em: http://download.inep.gov.br/educacao_basica/enem/downloads/2012/matriz_referencia_ enem.pdf. Acesso em 23/03/2020.

BRASIL. Base Nacional Comum Curricular (BNCC). Educação é a Base. Brasília: MEC/CONSED/UNDIME, 2017. Disponível em: <http://portal.mec.gov.br/index. php?option=com_docman\&view=download\&alias $=79611$-anexo-texto-bncc-aprovadoem-15-12-17-pdf\&category_slug=dezembro-2017-pdf\&Itemid=30192>. Acesso em 23/03/2020.

BROWN, T. Design Thinking: uma metodologia poderosa para decretar o fim das velhas ideias. Rio de Janeiro: Elsevier, 2010.

BROWNING, et al. Key concepts in modeling product development processes. Systems Engineering, v.9, n. 2, p. 104-128, 2006.

CHIN, G. Agile Project Management: how to succed in the face of changing projetc requirements. Amacom: New York, 2004.

CLARK, K. B., FUJIMOTO, T. Product development performance: strategy, organization and management in the world auto industry. Boston: Harvard Business School Press, 1991. 
CRAWFORD, L.; POLLACK, J.; ENGLAND, D. Uncovering the trens in Project management: jornal emphases over the last 10 years. International Journal of Project management, v. 24, n. 2, p. 175-184, 2006.

CROSS, N. The nature and nurture of design ability. Design Studies, v. 11, n.3, p. 127-140, 1990.

DOLABELA, F. A vez do sonho. São Paulo: Cultura, 2000.

DOLABELA, F. Pedagogia Empreendedora. São Paulo: Cultura, 2003.

DOLABELA, F. Ensino de empreendedorismo na Educação Básica como instrumento do desenvolvimento local sustentável. A METODOLOGIA PEDAGOGIA EMPREENDEDORA. Anais do XIV Seminário Nacional de Parques Tecnológicos e Incubadoras de Empresas e XII Workshop ANPROTEC, 2004.

DOLAN, R. J. Managing the new product development process. Boston: Addison Wesley, 1993.

FERNANDES, F. C. F.; GODINHO FILHO, M. Planejamento e Controle da Produçáo: dos fundamentos ao essencial. São Paulo: Atlas, 2010.

FORTUNA, A. M. EdaDe: a educação de crianças e jovens através do design. 2002. 357 f. Tese (Doutorado em Engenharia da Produção), Universidade Federal de Santa Catarina, Florianópolis. 2002.

GENTILI, P. O direito à educação e as dinâmicas de exclusão na América Latina.

Educação \& Sociedade, v. 30, n. 109, p. 1059-1079, 2009.

GIL, A. C. Como elaborar projetos de pesquisa. São Paulo: Atlas, 1991.

HIGHSMITH, J. Agile Project Management: creating innovative products. AddisonWesley: Boston, 2004.

IDEO. Design Thinking para educadores. São Paulo: IED, 2012.

NAGAI, W. A. \& IZEKI, C. A. Relato de experiência com metodologia ativa de aprendizagem em uma disciplina de programação básica com ingressantes dos cursos de Engenharia da Computação, Engenharia de Controle e Automação e Engenharia Elétrica. Revista RETEC, v. 4, p.1-10, 2013.

JUN, B. H.; SUH, W. H. A modeling framework for product development process considering it characteristics. Engineering Management, v. 55, n. 1, p. 103-119, 2008.

LIBERATO, A. C. T. Empreendedorismo na escola pública: despertando competências, promovendo a esperança. Disponível em: < http://www. bibliotecas.sebrae.com.br/chronus/ARQUIVOS_CHRONUS/bds/bds. nsf/3CBF34B0D06A6941832572B1006F3722/\$File/NT00035112.pdf>. Acesso em: 18 de novembro de 2015. 
LOBATO, D. M. Administraçáo estratégica: uma visão orientada para a busca de vantagens competitivas. Rio de Janeiro: Editoração, 2002.

LUCKESI, C. C. Avaliação da aprendizagem: componente do ato pedagógico. São Paulo, Cortez, 2011.

MINTZBERG, H. Criando organizaçóes eficazes. 2. ed. São Paulo: Atlas, 2006.

OLIVEIRA, M. A. Gestão e pedagogia empreendedoras urgem Educador-Empreendedor. Educação, Cultura e Comunicação, v. 1, n. 2, p. 55-60, 2011.

PINTO, A. S. S.; BUENO, M. R. P.; SILVA, M. A. F. A.; SELLMAN, M. Z. \& KOEHLER, S. M. F. Inovação Didática - Projeto de Reflexão e Aplicação de Metodologias Ativas de Aprendizagem no Ensino Superior: uma experiência com "peer instruction”. Janus, Lorena, v. 6, n. 15, p.75-87, 2012.

PUGH, S. Total Design: Integrated methods for successful product engeneering. 3 ed. UK, Addison-Wesley: Wokingham, 1990.

REGINALDO, T. Referenciais teóricos e metodológicos para a prática do design thinking na educaçáo básica. 2015. 206 f. Dissertação (Mestrado em Engenharia e Gestão do Conhecimento) - Universidade Federal de Santa Catarina, Florianópolis.

ROZENFELD, H. et al. Gestáo de Desenvolvimento de Produtos: uma referência para a melhoria do processo. São Paulo: Saraiva, 2006.

SANDERS, E. B. N. Virtuosos of the experience domain. Anais do IDSA Industrial Designers Society of America, Education Conference, Massachussets, USA, 2001.

SANTOS, R. V. Abordagem do processo de ensino e aprendizagem. Integraçáo, n. 40, p. 19-31, 2005.

SANTOS, C. P.; SOARES, S. R. Aprendizagem e relação professor-aluno na universidade: duas faces da mesma moeda. Estudos em Avaliação Educacional, São Paulo, v. 22, n. 49, p. 353-370. 2011.

SILVA, E. L.; MENEZES, E. M. Metodologia da pesquisa e elaboraçáo de dissertação. 3. ed. São Paulo: UFSC, 2001.

SMITH, P. G. Flexible Product Development: building agility for changing markets. Jossey-Bass: San Francisco, 2007.

WOUDHUYSEN, J. The craze for design thinking: Roots, a critique, and toward an alternative. Design Principles and Practices, v. 5, n. 6, p. 235-248, 2011. 